\author{
Şerif ÖZONGUN ${ }^{1}$ \\ Enver Murat DOLUNAY' \\ Mustafa PEKTAŞ2 \\ Gökhan ÖZTÜRK \\ Özgür ÇALHAN ${ }^{1}$ \\ Ersin ATAY1 \\ 1 TC GTHB, Meyvecilik Araş̧ırma Enstitüsü, 32500,
Eğirdir-Isparta /Türkiye
2 Batı Akdeniz Kalkınma Ajansı,
32200,Isparta/Türkiye
Sorumlu Yazar: serifozongun@yahoo.com
}

Anahtar Sözcükler:

Elma, anaç, verim, kalite, gelişme

\section{Farklı Klon Anaçları Üzerinde Bazı Elma Çeşitlerinin Verim ve Kalite Değişimleri}

\author{
Yield and Quality Alterations of Some Apple Cultivars on \\ Different Rootstock
}

Alınış (Received): 07.04.2015 Kabul tarihi (Accepted): 03.12.2015
Key Words:

Apple, rootstock, productivity, fruit quality, growth

\begin{abstract}
1 different apple variety (Mondial Gala, Skyline Supreme, Lutz Golden Granny Smith) grafted to clonal apple rootstocks (M9, M26, MM106, MM111) which have different vigour capacity were evaluated for yield development quality characterics in Eğirdir Fruit Research Institute in the study. Rootstocks had a significant effect on yield but they had no significant stable effect on fruit quality. M9 rootstock was determined for highest yield and Lutz Golden variety was determined for highest yield in varieties. Skyline Supreme variety was determined for lowest yield variety in Eğirdir conditions, MM111 rootstock is known semi-vigorous rootstocks but it was determined that it had some vigorous capacity with MM106 rootstock in the study.
\end{abstract}

\section{Giriş}

Meyvecilikte doğru anaç kullanımı, oluşturulacak bahçelerin en önemli öğelerinden birisini oluşturur. 1900'lü yılların başlarında farklı özelliklerde anaçlar elde edilmiştir. 1960'lı yıllardan itibaren Avrupa, Kuzey Amerika, Okyanusya ve bazı Güney Amerika ülkelerinde yeni anaçlarla kurulan bahçelerin sayısı hızla artmış, son yıllarda klonal bodur anaçlar çok yaygın şekilde kullanılmaya başlanmıştır. (Jackson 2003).

Türkiye'de 1970'li yıllardan sonra denemelerine başlanan bu anaçlara olan ilgi ancak 2000'li yıllara doğru artmıştır. Vejetatif olarak üretilen bodur ve yarı bodur klon anaçları, çöğür anaçlarına göre önemli avantajlara sahiptir. Bun avantajlardan bazılarl; dikim sıklığı ile karlılık daha yüksek, işçilik ve diğer üretim masrafları ise daha düşük olmasıdır (Özongun ve ark., 2002).

Anaç çeşitliliği bakımından en şanslı meyve türlerinin başında elma gelmektedir. Tamamlanmış ve halen yürütülmekte olan anaç ıslah programlarının pek çoğunun elma üzerine olması nedeniyle birçok anaç geliştirilmiştir. Çeşitli biyotik ve abiyotik stres koşullarına dayanıklı anaç ıslah çalışmaları ise halen devam etmektedir. Günümüzde yoğun dikim sistemlerine olan 
ilgi giderek artmakta ve bunu sağlayan anaçlarla ilgili çalışmalar da halen devam etmektedir (Way et al., 1990).

Bazen de soğuk bölgelerde Antonovka ve Bud. serisi anaçlarının tercih edilmesi gibi özel şartlara uyum sağlayabilen anaçlar da istenebilmektedir. Islah çalışmalarından elde edilen anaçların değişik bölgelerde performans çalışmalarının yapılması, anaçların çeșitle etkileşiminin belirlenmesi, ıslahın ikinci aşamasını oluşturmakta olup bu çalışmalar meyve üreticilerine yol gösterici olmaktadır.

Dünya'da uygun anaç-çeşit kombinasyonlarının belirlenmesi üzerine pek çok performans çalışması yapılmıştır (Burak ve ark., 1998 ; Pamir ve ark., 1997; Hampson and Kemp, 2003 ; Hussein and Slack, (1994).

Bu çalışmada, farklı gelişim kuvvetine sahip dört klonal elma anacı (M9, M26, MM106 ve MM111) üzerinde dört elma çeşidinin (Mondial Gala, Lutz Golden, Skyline Supreme, Granny Smith) verim ve meyve kalitesi açısından performans durumları EğirdirIsparta koşullarında incelenmiştir.

\section{MATERYAL ve YÖNTEM}

Denemede M9, M26, MM106 ve MM111 anaçları, çeşit olarak da Skyline Supreme, Lutz Golden, Granny Smith ve Mondial Gala kullanılmıştır. Deneme, Eğirdir Bahçe Kültürleri Araştırma Enstitüsü arazisi ve pomoloji laboratuvarında yürütülmüştür.

Çeşitler, 1998 yılının Ağustos ayında anaçlara aşılanmış ve 1999 yılı Kasım ayında deneme parseline dikilmiştir. Deneme bahçesi; M9 anacında $3 \times 1.5 \mathrm{~m}$, M26 anacında $3 \times 2$ m, MM106 anacında $4 \times 3 \mathrm{~m}$ ve MM111 anacında da $6 \times 5 \mathrm{~m}$ sıra arası ve üzeri mesafe ile tesis edilmiştir.

M9 ve M26 anacına Hybrid Tree Cone (HYTEC), MM106 ve MM111 anaçlarına Merkezi Lider terbiye sistemi uygulanmıştır. Çalışmada fenolojik gözlemler, pomolojik analizler ile verime ilişkin hesaplamalar yapılmıştır.

\section{Verim ve Pomolojik Özellikler}

Dikimden sonraki dördüncü yıldan itibaren pomolojik çalışmalara başlanmış ve 8 yaşına kadar devam edilmiştir. Pomolojik analizler her ağaçtan alınan 15 meyve ile; meyve eni $(\mathrm{mm})$, boyu $(\mathrm{mm})$, ortalama meyve ağırlığı (g), meyve rengi (her bir meyvenin ekvatoral bölgesinden karşılıklı iki noktasından Minolta CR 400 cihazı ile $L^{*}, a^{*}, b^{*}$, değerleri ölçülmüş, Hue açı $\left(h^{\circ}\right)$ ve Kroma $\left(C^{*}\right)$ değerleri hesaplanmıştır), meyve eti sertliği kg olarak 11.1 mm'lik uç ile $10 \mathrm{~mm}$ derinliğe batırılarak ölçülmüş, daha sonra Newton birimine çevrilmiştir, $\mathrm{pH}$, suda çözünebilir kuru madde miktarı (SÇKM - \%), titre edilebilir asitlik (TA - \%) (Karaçalı, 2009), nişasta testi (0-10 skalası) (Eren, 2003), ağaç başına yıllık verim ortalaması (kg/ağaç), ağaçlar verime yattığı yıldan itibaren kümülatif verim (kg/ağaç), gövde kesit alanına isabet eden kümülatif verim $\left(\mathrm{kg} / \mathrm{cm}^{2}\right)$, meyve tasnifi $(80$ $\mathrm{mm}$ ve üzeri, $70-79 \mathrm{~mm}$ arası, $65-69 \mathrm{~mm}$ arası ve $65 \mathrm{~mm}$ altı şeklinde son iki yılda her tekerrürde tesadüfen seçilen 2'şer ağaçta kumpas yardımı ile ölçülmüştür) ve hasat önü döküm miktarı kriterlerinde yürütülmüştür.

\section{Morfolojik değerlendirmeler}

Denemenin son yılında ağaçların şekil ve gelişimleri incelerek, ağaçlarda yükseklik, taç genişliği ve gövde çevresi ölçümleri yapılmıştır (Burak ve ark., 1994).

\section{Fenolojik gözlemler}

Dikimden sonraki 3. yıl fenolojik gözlemlere başlanmış ve ağaçlar 8 . vegetasyonu tamamlayıncaya kadar devam edilmiştir.

Deneme, bölünen bölünmüş bloklar deneme desenine göre 4 tekerrürlü kurulmuş, dikim sistemleri ana parsel, çeşitler alt parsel olacak şekilde her parselde 5 ağaç yer almıştır. Pomolojik analiz, verim ve kalite verileri, JMP istatistik programı yardımı ile değerlendirilmiştir.

\section{ARAŞTIRMA BULGULARI ve TARTIŞMA \\ Verim ve Pomolojik Özellikler}

Son yıllarda yapılan çalışmalarda ağaçların taç genişliği ve boyu gibi ölçütlerden ziyade gövde kesit alanı (GKA) ve gövde kesit alanına verim (GKAV) daha fazla kullanılmaktadır (Barritt 1992; Schupp 1992; Ferree 1992; Granger et al., 1992). Bu nedenle anaçların verim üzerine etkilerinin değerlendirilmesinde en çok gövde kesit alanına verim (GKAV) değerlerinden yararlanılmıştır.

Çeşit anaç kombinasyonlarının gövde kesit alanları (GKA) Çizelge 1'de verilmiştir. Deneme süresince çeşit anaç kombinasyonlarından elde edilen dekara verim değerleri yıllar itibariyle Çizelge 2 ve Şekil 1'de verilmiştir. Anaçların ağaç başı verimleri incelendiğinde (Şekil 2), anaç kuvveti ve oluşturdukları taç yapısına paralel değerler elde edilmiştir. Sonuçlar beklentiler doğrultusunda olmuş, bodur anaçlardan yarı bodur anaçlara doğru gidildikçe, ağaç kuvveti artıştı ile gövde kesit alanı artmıştır. GKAV incelendiğinde (Çizelge 1.); Granny Smith çeşidinde verim en yüksek M9 (3.98 $\mathrm{kg} / \mathrm{cm}^{2}$ ) anacında elde edilmiş sonra sırasıyla M26, MM106 ve MM111 anaçları $3.06 \mathrm{~kg} / \mathrm{cm}^{2}, 2.78 \mathrm{~kg} / \mathrm{cm}^{2}$, $2.06 \mathrm{~kg} / \mathrm{cm}^{2}$ verimler ile takip etmişlerdir. Tam verim çağındaki MM111 (62.27 kg/ağaç) ve MM106 (61.95 
$\mathrm{kg} / \mathrm{ağaç)} \mathrm{ağaçları,} \mathrm{verim} \mathrm{bakımından} \mathrm{aynı} \mathrm{grupta} \mathrm{yer}$ almışlar fakat GKAV bakımından MM106 anacının verim etkinliği daha yüksek olmuştur. Nitekim benzer şekilde Parry and Baird, (1971), M9 ve M26 bodur anaçlarının ağaç başı verimleri aynı grupta olmasına rağmen GKAV açısından M9'un verim etkinliği M26 anacına göre daha yüksek olduğu belirlenmiştir. Verim-gövde kesit alanı ve anaçlar arasındaki benzer ilişki benzer sonuçlar diğer bazı araştırmalarda da tarafından belirtilmiştir (Barrit et al., 1997; Öz ve ark., 1993).

Çizelge 1. Anaç-çeşit kombinasyonlarının gövde kesit alanları, verim ve hasat önü döküm değerleri Table 1. Variety/rootstock combinations trunk cross sectional area (TCSA), yield and preharvest fall values

\begin{tabular}{|c|c|c|c|c|c|}
\hline Çeşit & Anaç & $\begin{array}{c}\text { Gövde Kesit } \\
\text { Alanı }\left(\mathrm{cm}^{2}\right)\end{array}$ & $\begin{array}{c}\text { Verim } \\
\left(\mathbf{k g ~ a g ̆ a c ̧}^{-1}\right)\end{array}$ & $\begin{array}{c}\text { GKAV } \\
\left(\mathrm{kg} \mathrm{cm}^{-2}\right)\end{array}$ & $\begin{array}{l}\text { Hasat Önü } \\
\text { Döküm (\%) }\end{array}$ \\
\hline \multirow{5}{*}{ Mondial Gala } & M9 & $67.75^{d}$ & $37.44^{\mathrm{b}}$ & $5.25^{\mathrm{a}}$ & $6^{c}$ \\
\hline & M26 & $90.96^{c}$ & $41.65^{b}$ & $3.18^{b}$ & $7^{c}$ \\
\hline & MM106 & $109.12^{\mathrm{a}}$ & $95.5^{\mathrm{a}}$ & $3.28^{\mathrm{b}}$ & $11^{\mathrm{a}}$ \\
\hline & MM111 & $99.85^{b}$ & $80.28^{a}$ & $2.93^{b}$ & $9^{b}$ \\
\hline & & $* *$ & $* *$ & ${ }^{* *}$ & $* *$ \\
\hline \multirow{5}{*}{ Skyline Supreme } & M9 & $68.35^{c}$ & $26.54^{b}$ & $2.71^{\mathrm{a}}$ & $6^{b}$ \\
\hline & M26 & $86.05^{b}$ & $24.82^{\mathrm{b}}$ & $1.78^{c}$ & $7^{b}$ \\
\hline & MM106 & $92.40^{\mathrm{a}}$ & $52.35^{\mathrm{a}}$ & $2.30^{\mathrm{b}}$ & $11^{\mathrm{a}}$ \\
\hline & MM111 & $92.03^{a}$ & $44.82^{\mathrm{a}}$ & $1.77^{c}$ & $7^{b}$ \\
\hline & & $* *$ & $* *$ & ${ }^{* *}$ & ** \\
\hline \multirow{5}{*}{ Lutz Golden } & M9 & $71.76^{c}$ & $37.30^{\mathrm{b}}$ & $4.37^{a}$ & $6^{c}$ \\
\hline & M26 & $83.83^{b}$ & $34.11^{b}$ & $3.24^{b}$ & $6^{c}$ \\
\hline & MM106 & $90.75^{a}$ & $65.96^{\mathrm{a}}$ & $3.97^{\mathrm{a}}$ & $12^{\mathrm{a}}$ \\
\hline & MM111 & $90.75^{a}$ & $75.34^{\mathrm{a}}$ & $3.98^{\mathrm{a}}$ & $9^{b}$ \\
\hline & & $* *$ & $* *$ & ${ }^{* *}$ & ${ }^{* *}$ \\
\hline \multirow{5}{*}{ Granny Smith } & M9 & $73.21^{c}$ & $42.47^{b}$ & $3.98^{\mathrm{a}}$ & $5^{c}$ \\
\hline & M26 & $68.61^{c}$ & $40.12^{b}$ & $3.06^{b}$ & $7^{b}$ \\
\hline & MM106 & $90.81^{\mathrm{a}}$ & $61.95^{\mathrm{a}}$ & $2.78^{b}$ & $11^{\mathrm{a}}$ \\
\hline & MM111 & $81.73^{b}$ & $62.27^{\mathrm{a}}$ & $2.06^{c}$ & $7^{b}$ \\
\hline & & $* *$ & $* *$ & $* *$ & $* *$ \\
\hline
\end{tabular}

${ }^{*} p<0.05 ; * * 0.01 ; O D=$ Önemli değil

Çizelge 2. Anaç-çeşit kombinasyonlarının yıllara göre dekara verim değerleri $\left(\mathrm{kg} \mathrm{da}^{-1}\right)$ Table 2. Variety/rootstock combinations according to years $\left(\mathrm{kg} \mathrm{da}^{-1}\right)$

\begin{tabular}{|c|c|c|c|c|c|c|c|c|c|c|}
\hline \multirow{2}{*}{ Çeşit } & \multirow{2}{*}{ Anaç } & \multirow{2}{*}{$\begin{array}{c}\text { Dekara } \\
\text { Ağaç Sayısı }\end{array}$} & \multirow{2}{*}{$\frac{2002}{2 . y ı l}$} & \multirow{2}{*}{$\frac{2003}{3 . y ı l}$} & \multirow{2}{*}{$\frac{2004}{4 . y ı l}$} & \multirow{2}{*}{$\begin{array}{c}2005 \\
5 . y 11\end{array}$} & \multirow{2}{*}{$\frac{2006}{6 . y ı l}$} & \multirow{2}{*}{$\frac{2007}{7 . y ı l}$} & \multirow{2}{*}{$\begin{array}{c}2008 \\
8 . y ı l\end{array}$} & \multirow{2}{*}{ TOPLAM } \\
\hline & & & & & & & & & & \\
\hline \multirow{4}{*}{$\begin{array}{l}\text { Mondial } \\
\text { Gala }\end{array}$} & M9 & 222 & 43 & 637 & 6141 & 6132 & 6937 & 4369 & 10909 & 35168 \\
\hline & M26 & 166 & 390 & 958 & 4836 & 3930 & 5934 & 3479 & 8045 & 27572 \\
\hline & MM106 & 83 & 487 & 2123 & 3684 & 6600 & 3818 & 3982 & 11187 & 31882 \\
\hline & MM111 & 33 & 15 & 53 & 744 & 608 & 881 & 939 & 4359 & 7599 \\
\hline \multirow{4}{*}{$\begin{array}{l}\text { Skyline } \\
\text { Supreme }\end{array}$} & M9 & 222 & 0 & 150 & 3463 & 5044 & 1338 & 5027 & 5671 & 20693 \\
\hline & M26 & 166 & 0 & 917 & 3227 & 5734 & 1188 & 2908 & 4349 & 18323 \\
\hline & MM106 & 83 & 175 & 1219 & 3006 & 6625 & 338 & 3344 & 5346 & 20053 \\
\hline & MM111 & 33 & 0 & 13 & 421 & 1705 & 235 & 1011 & 1944 & 5330 \\
\hline \multirow{4}{*}{$\begin{array}{l}\text { Lutz } \\
\text { Golden }\end{array}$} & M9 & 222 & 0 & 697 & 5759 & 6046 & 7361 & 7109 & 8708 & 35680 \\
\hline & M26 & 166 & 267 & 1435 & 5759 & 5295 & 6616 & 4352 & 7024 & 30749 \\
\hline & MM106 & 83 & 249 & 1949 & 5621 & 6670 & 3581 & 5967 & 4926 & 28963 \\
\hline & MM111 & 33 & 0 & 189 & 949 & 731 & 1542 & 2230 & 2742 & 8383 \\
\hline \multirow{4}{*}{$\begin{array}{l}\text { Granny } \\
\text { Smith }\end{array}$} & M9 & 222 & 76 & 234 & 3885 & 6005 & 6402 & 8170 & 8303 & 33075 \\
\hline & M26 & 166 & 307 & 444 & 2170 & 5066 & 3899 & 3497 & 8094 & 23477 \\
\hline & MM106 & 83 & 425 & 456 & 3885 & 5045 & 2365 & 4919 & 5403 & 22499 \\
\hline & MM111 & 33 & 30 & 30 & 406 & 609 & 1015 & 1644 & 2478 & 6212 \\
\hline
\end{tabular}




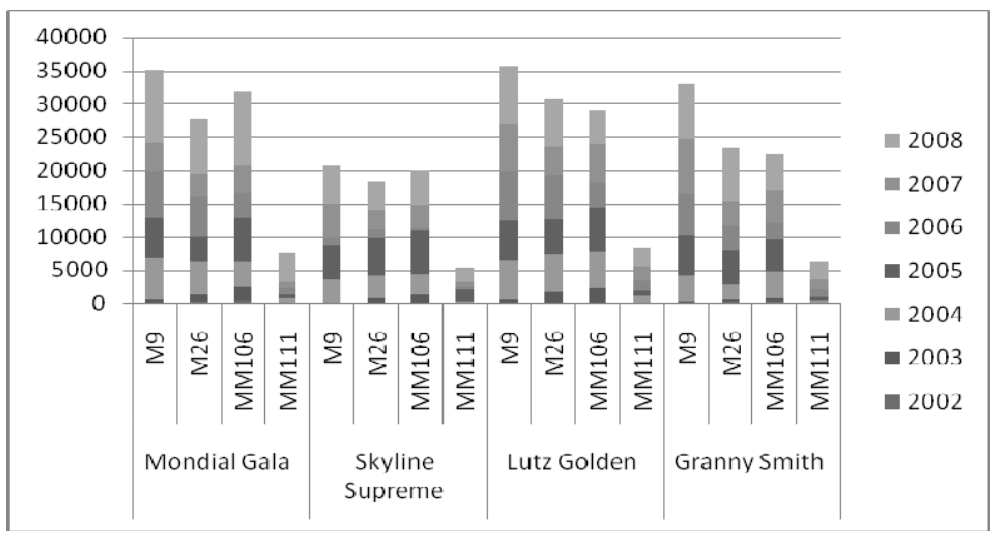

Şekil 1. Anaç-çeşit kombinasyonlarının yıllara göre dekara verim değerleri $\left(\mathrm{kg} \mathrm{da}^{-1}\right)$ Figue 1. Variety/rootstock combinations according to years $\left(\mathrm{kg} \mathrm{da}^{-1}\right)$

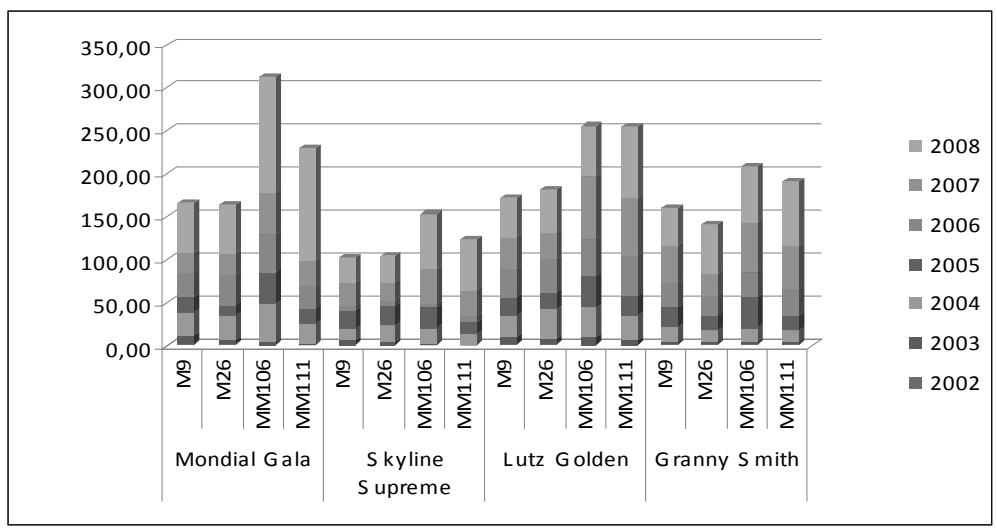

Şekil 2. Anaç-çeşit kombinasyonları ait ağaç başına kümülatif verim ( $\mathrm{kg}$ ) değerleri Figure 2. Variety/rootstock cobinations cumulative yield values per tree ( $\mathrm{kg}$ )

Çeşitlere ait meyve iriliği dağılımında, istatistiksel analiz uygulanmamış sadece son 2 yılın meyve iriliği dağılımı belirlenerek ortalaması alınmıştır (Çizelge 3). Mondial Gala çeşidinde M9 anacı üzerinde meyve iriliği en fazla (\% 48 oranında) $60-65 \mathrm{~mm}$ arasında oluşmuştur. $60-65 \mathrm{~mm}$ aralığını \% 34 oranı ile 66-70 $\mathrm{mm}$ takip etmiştir. Mondial Gala çeşidi küçük-orta irilikte meyveye sahip olduğundan (Hampson and Kemp, 2003) en fazla 60-70 mm arasında meyve oluşturmuştur. Fakat M9'a göre kuvvetli olan M26, MM106 ve MM111 anaçlarında 71-75 mm arasındaki meyve oranı daha yüksek gerçekleşmiş, meyve iriliğinin dağılımındaki yeknesaklık azalmıştır. MM111 anacında meyve iriliği oransal olarak artmış, $66-75 \mathrm{~mm}$ arasında yoğunlaşmıştır.

Lutz Golden çeşidinde bütün anaçlar üzerinde meyve iriliği 66-75 mm arasında yoğunlaşmıştır. MM111 (71-75 mm aralığında \% 42) haricindeki diğer anaçlarda 66-70 mm aralığında, \% olarak en fazla meyve sayısı elde edilmiştir. Lutz Golden çeşidinin verimli olması ile meyve iriliğinin dağılımının dar bir bantta gerçekleşmesi arasında ilişki olduğu düşünülmektedir.
Skyline Supreme çeşidinde meyve iriliği dağılımı bakımından, bodur ve yarı bodur anaçlar üzerinde farklılık görülmüştür. Bodur anaçların meyve iriliği dağılımı daha geniş aralıkta gerçekleşirken yarı bodur anaçlar daha iri ve daha dar sınıf aralığında meyveler oluşturmuşlardır. MM106 anacı üzerinde \% 46 ile 81$85 \mathrm{~mm}$ arasında, MM111 anacı ise \% 40 ile $81-85 \mathrm{~mm}$ arasında en yoğun meyve iriliği gerçekleşmiştir. Bu durumun sebebi olarak Skyline Supreme çeşidinin verimsiz olmasına bağlı olarak meyve iriliğinin yarı bodur anaçlar üzerinde arttığı düşünülmektedir.

Granny Smith çeşidi de Lutz Golden ve Mondial Gala çeşitleri gibi verimli olması nedeni ile meyve iriliği dağılımı Skyline Supreme çeşidi gibi dar bir bantta gerçekleşmiştir. Granny Smith çeşidi, orta-iri yapıda meyveler oluşturmuştur. Anaçların meyve iriliğine etkileri farklı olmuştur. M9 ve MM106 anaçlarında meyve iriliği en çok 76-80 mm (\% 33) ve (\% 38) M26 ve MM111 anaçlarına ise $81-85 \mathrm{~mm}$ arasında (\% 47 ve 45 ) olmuştur. 
Çizelge 3. Çeşitlerin anaçlar üzerindeki meyve iriliği dağılımı ( \% ) ( mm ) Table 3. Fruit size ratios on rootstock/variety combinations $(\%)(\mathrm{mm})$

\begin{tabular}{|c|c|c|c|c|c|c|c|}
\hline & $60<$ & $60-65$ & $66-70$ & 71-75 & $76-80$ & $81-85$ & 85> \\
\hline \multicolumn{8}{|c|}{ Mondial Gala } \\
\hline M9 & 16 & 48 & 34 & 1 & 1 & & \\
\hline M 26 & 2 & 18 & 53 & 27 & & & \\
\hline MM 106 & 1 & 25 & 45 & 28 & 1 & & \\
\hline MM 111 & & 20 & 52 & 26 & 2 & & \\
\hline \multicolumn{8}{|c|}{ Skyline Supreme } \\
\hline M 9 & 2 & 2 & 20 & 13 & 27 & 20 & 16 \\
\hline M 26 & & 2 & 10 & 27 & 26 & 21 & 14 \\
\hline MM 106 & & & & 14 & 22 & 46 & 20 \\
\hline MM 111 & & & 2 & 12 & 23 & 40 & 24 \\
\hline \multicolumn{8}{|c|}{ Lutz Golden } \\
\hline M9 & 1 & 17 & 38 & 36 & 8 & & \\
\hline M 26 & 1 & 23 & 36 & 29 & 1 & & \\
\hline MM 106 & 6 & 28 & 30 & 35 & 1 & & \\
\hline MM 111 & 5 & 17 & 34 & 42 & 2 & & \\
\hline \multicolumn{8}{|c|}{ Granny Smith } \\
\hline M 9 & & & 2 & 8 & 33 & 29 & 28 \\
\hline M 26 & & & & 3 & 15 & 47 & 35 \\
\hline MM 106 & & & & 9 & 38 & 32 & 21 \\
\hline MM 111 & & & & 21 & 45 & 21 & 13 \\
\hline
\end{tabular}

Pazarlama açısından meyve çapı önemli bir kriterdir. Fakat bu çalışmada anaçların, meyve iriliğine etkisinde bir korelasyon bulunamamıştır. Öz ve ark., (1993)'ın, Yalova koşullarında M9, MM106, MM111ve çöğür anaçları üzerinde yetişen Golden Delicious, Starking Delicious ve Granny Smith elma çeşitleri ile yürüttükleri çalışmada olduğu gibi,
M9 anacının olumlu etkisi bu çalışmada bütün çeşitlerde gözlemlenememiştir. Ferree (1992)'de yürüttüğü anaç-çeşit performans çalışmasında meyve iriliği üzerine anaçların fazla etkisinin olmadığını bildirmiştir.

Elma çeşitlerinin pomolojik özelliklerine ait değerler Çizelge 4'de verilmiştir.

Çizelge 4. Anaç-çeşit kombinasyonlarının pomolojik analiz değerleri ( $\mathrm{kg}$ )

Table 4. Variety/rootstock combinations pomologic analyse vaules $(\mathrm{kg})$

\begin{tabular}{|c|c|c|c|c|c|c|c|c|c|}
\hline Çeşit & Anaç & $\begin{array}{c}\text { Meyve } \\
\text { Ağırlığı (g) }\end{array}$ & M. Eni (mm) & M. Boyu (mm) & $\begin{array}{l}\text { M.Eti Sertliği } \\
\text { (N) }\end{array}$ & $\begin{array}{c}\text { SÇKM } \\
(\%)\end{array}$ & $\begin{array}{c}\text { M.S. } \\
\text { Uzu. (mm) }\end{array}$ & $\begin{array}{l}\text { M. Asi. } \\
\text { (\%) }\end{array}$ & pH \\
\hline \multirow{5}{*}{$\begin{array}{l}\text { Mondial } \\
\text { Gala }\end{array}$} & M9 & $147^{b}$ & $69.04^{\mathrm{ab}}$ & 61.73 & $90.70^{\mathrm{b}}$ & $13.03^{\mathrm{a}}$ & 23.31 & $0.30^{d}$ & 3.70 \\
\hline & M26 & $160^{\mathrm{a}}$ & $69.95^{\mathrm{a}}$ & 61.95 & $90.02^{b}$ & $12.59^{b}$ & 23.29 & $0.33^{c}$ & 3.67 \\
\hline & MM106 & $148^{b}$ & $67.65^{b}$ & 60.86 & $94.63^{\mathrm{ab}}$ & $12.48^{\mathrm{b}}$ & 24.05 & $0.35^{b}$ & 3.66 \\
\hline & MM111 & $149^{b}$ & $66.09^{c}$ & 59.95 & $97.67^{a}$ & $12.64^{\mathrm{b}}$ & 23.25 & $0.37^{\mathrm{a}}$ & 3.64 \\
\hline & & $* *$ & ** & $\mathrm{OD}$ & * & ** & $O D$ & ** & $\mathrm{OD}$ \\
\hline \multirow{5}{*}{$\begin{array}{l}\text { Skyline } \\
\text { Supreme }\end{array}$} & M9 & $269^{a}$ & 82.31 & $73.97^{\mathrm{a}}$ & 94,14 & $14.24^{b}$ & 19.00 & $0.29^{c}$ & 3.82 \\
\hline & M26 & $248^{b}$ & 82.71 & $73.93^{\mathrm{a}}$ & 92,86 & $13.29^{c}$ & 19.81 & $0.37^{\mathrm{a}}$ & 3.81 \\
\hline & MM106 & $242^{b}$ & 80.83 & $71.04^{b}$ & 96,10 & $14.28^{b}$ & 20.26 & $0.32^{\mathrm{b}}$ & 3.86 \\
\hline & MM111 & $247^{b}$ & 80.06 & $71.59^{b}$ & 98,74 & $15.74^{\mathrm{a}}$ & 19.60 & $0.30^{\mathrm{b}}$ & 3.80 \\
\hline & & * & OD & ${ }^{* *}$ & OD & $* *$ & $\mathrm{OD}$ & $* *$ & $\mathrm{OD}$ \\
\hline \multirow{5}{*}{$\begin{array}{l}\text { Lutz } \\
\text { Golden }\end{array}$} & M9 & $176^{\mathrm{b}}$ & $72.11^{b}$ & $67.87^{b c}$ & 82,76 & $15.77^{\mathrm{ab}}$ & $23.80^{\mathrm{bc}}$ & $0.47^{\mathrm{ab}}$ & 3.45 \\
\hline & M26 & $188^{\mathrm{a}}$ & $74.00^{\mathrm{a}}$ & $69.34^{\mathrm{ab}}$ & 84,43 & $15.05^{\mathrm{b}}$ & $25.21^{\mathrm{ab}}$ & $0.46^{\mathrm{ab}}$ & 3.44 \\
\hline & MM106 & $183^{\mathrm{ab}}$ & $72.86^{\mathrm{ab}}$ & $69.98^{\mathrm{a}}$ & 87,17 & $16.34^{\mathrm{a}}$ & $25.93^{\mathrm{a}}$ & $0.49^{\mathrm{a}}$ & 3.42 \\
\hline & MM111 & $162^{c}$ & $69.83^{c}$ & $66.86^{c}$ & 86,49 & $16.41^{\mathrm{a}}$ & $22.91^{c}$ & $0.45^{\mathrm{b}}$ & 3.40 \\
\hline & & ** & ** & *** & OD & $*$ & 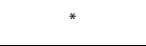 & 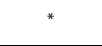 & $\mathrm{OD}$ \\
\hline \multirow{5}{*}{$\begin{array}{l}\text { Granny } \\
\text { Smith }\end{array}$} & M9 & $214^{b}$ & $78.81^{b}$ & $69.61^{b}$ & 110,71 & $14.31^{b}$ & $17.19^{\mathrm{a}}$ & $0.80^{\mathrm{b}}$ & $3.12^{\mathrm{a}}$ \\
\hline & M26 & $220^{\mathrm{ab}}$ & $78.44^{b}$ & $70.79^{\mathrm{ab}}$ & 110,81 & $15.30^{\mathrm{a}}$ & $15.30^{\mathrm{b}}$ & $0.84^{\mathrm{a}}$ & $3.18^{\mathrm{a}}$ \\
\hline & MM106 & $229^{a}$ & $79.81^{\mathrm{ab}}$ & $72.54^{\mathrm{a}}$ & 107,96 & $13.87^{c}$ & $18.34^{\mathrm{a}}$ & $0.79^{b}$ & $3.02^{\mathrm{b}}$ \\
\hline & MM111 & $228^{a}$ & $80.68^{a}$ & $71.88^{\mathrm{a}}$ & 106,10 & $14.01^{b c}$ & $17.22^{\mathrm{a}}$ & $0.79^{b}$ & $3.06^{b}$ \\
\hline & & ${ }^{*}$ & * & $*$ & $O D$ & $* *$ & $* *$ & $* *$ & ** \\
\hline
\end{tabular}

${ }^{*} p<0.05 ; * * 0.01 ; O D=$ Önemli değil 
Meyve iriliği açısından Granny Smith ve Skyline Supreme çeşitleri orta-iri, Lutz Golden orta, Mondial Gala ise küçük-orta sınıf meyveler oluşturmuştur. Hussein and Slack (1994), meyve iriliği üzerine anaççeşit kombinasyonunun önemli olduğunu, Red Delicious ve Granny Smith çeşitlerinin MM106 anacı üzerinde daha kuvvetli geliştiklerini, Gala çeşidinde ise böyle bir etkinin olmadığını bildirmişlerdir. Fakat çalışmada istatistiki açıdan anaçların meyve ağırlığına etkilerinin olduğu tespit edilmesine rağmen MM106 anacının meyve ağırlık artışını artırdığı yönünde açık bir sonuç bulunamamıştır. Çeşit özelliklerinden kaynaklanan farklılıklar daha dikkat çekicidir. Tustin (1990), yaptığı çalışmada Gala çeşidinin meyve ağırlığını benzer şekilde tespit etmiştir.

Meyve boyu ve eni açısından anaçlar arasında istatistiki olarak farklılık tespit edilmiştir. Meyve şekli anaçların etkisi ile değişmektedir. Fakat anaç kuvveti ile meyve en/boy oranı arasında bir ilişki bulunmamıştır. Barritt et al., (1994), yaptıkları benzer bir çalışmada Delicious çeşidini 32 anaç üzerinde 2 yıl boyunca denemeye almış ve kuvvetli anaçlarda meyvelerin daha uzun olduğunu tespit etmişlerdir.

Meyve eti sertliği açısından Mondial Gala çeşidinde anaçlar arasında bir fark görülmesine rağmen diğer çeşitlerde fark tespit edilememiştir.

SÇKM açısından anaç ve çeşitler arasında istatistiki açıdan fark bulunmuş fakat bir korelasyon tespit edilememiştir. Bu bulgulara paralel olarak Tomala et al., (2008), 14 anaç ile yürüttükleri çalışmada meyve eti sertliği ve suda çözünebilir kuru madde miktarları (SÇKM) üzerine net bir ilişki olmadığını bildirmişlerdir. Koyuncu ve ark., (2003), SÇKM oranlarına anaçların etkilerinin hep aynı yönde olmayacağını, hatta deneme yılları boyunca dahi değişebileceğini bildirmişlerdir.

Titre edilebilir asitlik değerleri bakımından, anaççeşit kombinasyonlarında bütün çeşitlerde istatistiki olarak farklılık bulunmuştur. Fakat belirlenen fark, çeşitler arasında aynı yönde olmamıştır. Anaçlar arasındaki farklar yapılan değişik çalışmalarda bulunan çeşit özelliklerini gösteren sonuçlarla benzerlik göstermektedirler (Özongun ve ark., 2004; 2009; Eren, 2003). Koyuncu ve ark., (2003) ise Eğirdir bölgesinde M9 ve MM106 anaçları üzerine yetiştirilen bazı elma çeşitlerinde meyvenin titre edilebilir asitlik oranı bakımından fark bulmamışlardır.

Meyve suyunda yapılan $\mathrm{pH}$ analizlerin neticesinde, anaç-çeşit ilişkileri açısından 4 çeşit içerisinde sadece Granny Smith çeşidinde istatistiki açıdan fark bulunmuştur.

Hasat önü döküm oranları ile anaç kuvveti arasında ilişki tespit edilmiş, yarı bodur anaçlı ağaçlarda bütün çeşitlerde hasat önü dökümü, bodur anaçlara (M9, M26) göre daha yüksek gerçekleşmiştir.
Taraen et al. (2003), M9 ve MM106 anaçlarının Starking Delicious çeşidi üzerine etkilerini belirlemek için yaptıkları çalışmada, MM106 anacının Starking Delicious çeşidinde hasat önü dökümünü artırdığını bildirmişlerdir.

Meyvelerde renklenme üzerine anaçların etkileri $L^{*}, a{ }^{*}, b^{*}$, Hue $\left(h^{\circ}\right)$ ve Kroma $\left(C^{*}\right)$ değerlerinden bazılarında istatistiki açıdan önemli bulunmuştur (Çizelge 5). Çeşitlerin anaçlar üzerindeki 'a*' değerine etkisi ise bütün çeşitlerde istatistiki açıdan önemli bulunmuştur. Çalışmada genellikle çeşitlerin anaçlar üzerindeki $\left(b^{*}\right)$ değerleri arasında farklııık görülmemiştir. 'b" değerleri bütün ölçümlerde (+) değerler alıp sarı renge doğru bir kayma görülmüştür.

Anaçların, çeşitlerin meyve kabuk rengindeki $C^{*}$ değerine etkileri incelendiğinde, Granny Smith dışında anaç-çeşitler arasında istatistiki açıdan fark çıkmamıştır. Granny Smith çeşidinde de MM111 anacı üzerindeki çeşidin meyvelerinde $C^{*}$ değeri en düşük çıkmıştır. Bunun da kabuk üst yüzeyinde pus (mum) tabakasının daha fazla olmasıyla rengin yoğunluğunun azalmasında etkili olduğu düşünülmektedir. Rengin insan gözüyle algılandığı rengi ifade eden $\mathrm{h}^{\circ}$ değerleri incelendiğinde ise bütün çeşitlerde anaçlar arasında istatistiki olarak fark görülmüştür. Fakat anaçlar arasındaki farklılıkta bütün çeşitlerde, farklı anaçlar yüksek değerler almıştır.

Renk değerleri birlikte değerlendirildiğinde tüm çeşitlerde anaçların etkileri benzer şekilde görülmemiştir. Koyuncu ve ark., (2003), Eğirdir bölgesinde $M 9$ ve MM106 anaçları ile yürüttükleri çalışmada meyve kabuk rengi açısından M9 anacının etkisini daha olumlu bulmuşlardır. Fakat çalışmamızda net bir iliş̧ki bulunamamıştır. Koyuncu ve ark., (2003), meyve rengi ile ilgili olarak, Granny Smith elma çeşidinde anaçların renk değerleri üzerine etkisinin olmadığını bildirmişlerdir.

\section{Fenolojik Gözlem Sonuçları}

Çalışma sürecinde her yıl düzenli olarak fenolojik aşamalar kayıt altına alınmıştır (Çizelge 6). Fenolojik evreler üzerine anaçların etkisi olmamış, bazı yıllar çiçeklenme tarihlerinde 1-2 günlük farklar görülmesine rağmen bir ilişki bulunamamıştır. Deneme süresince bölgede bazı yıllar etkili olan ilkbahar geç donlarının, verim açısından herhangi bir olumsuz etkisi gözlemlenmemiştir.

Hasat kriterleri göz önünde bulundurularak yapılan hasat tarihleri, literatür ile uyum göstermiştir. Hasat tarihinin belirlenmesinde Eren (2003)'in bazı elma çeşitlerinde oluşturduğu nişasta skalasından yararlanılmış ve anaçların hasat tarihine etkileri yorumlanmaya çalışılmışır. Anaçların hasat tarihine nişasta testine göre yaklaşık 2-3 günlük etkisi olduğu görülmüştür. Hasat tarihlerinin, anaç bodurluğu arttıkça biraz daha erken olduğu tespit edilmiştir. 
Çizelge 5. Anaç-çeşit kombinasyonlarının renk değerleri Table 5. Color values of variety/rootstock combinations

\begin{tabular}{|c|c|c|c|c|c|c|}
\hline Çeşit & Anaç & $\left(\mathbf{L}^{*}\right)$ & $\left(a^{*}\right)$ & $\left(\mathbf{b}^{*}\right)$ & Kroma (C*) & Hue Açısı ${ }^{0}$ \\
\hline \multirow{5}{*}{ Mondial Gala } & M9 & 63.04 & $12.22^{b}$ & 26.53 & 34.90 & $68.12^{\mathrm{a}}$ \\
\hline & M26 & 63.26 & $12.23^{b}$ & 26.00 & 33.60 & $67.57^{\mathrm{a}}$ \\
\hline & MM106 & 63.18 & $14.58^{a b}$ & 24.98 & 34.04 & $63.70^{\mathrm{a}}$ \\
\hline & MM111 & 60.67 & $18.48^{a}$ & 24.28 & 34.41 & $56.98^{b}$ \\
\hline & & $O D$ & $* *$ & OD & $O D$ & $* *$ \\
\hline \multirow{5}{*}{$\begin{array}{l}\text { Skyline } \\
\text { Supreme }\end{array}$} & M9 & $46.44^{a}$ & $28.47^{\mathrm{ab}}$ & $24.87^{\mathrm{ab}}$ & 29.81 & $30.13^{b}$ \\
\hline & M26 & $47.00^{a}$ & $24.94^{b}$ & $27.44^{a}$ & 28.34 & $37.99^{a}$ \\
\hline & MM106 & $43.08^{b}$ & $30.15^{a}$ & $23.07^{b}$ & 30.74 & $27.65^{\mathrm{b}}$ \\
\hline & MM111 & $46.05^{a}$ & $27.72^{\mathrm{ab}}$ & $23.98^{b}$ & 30.00 & $31.37^{\mathrm{a}}$ \\
\hline & & * & * & * & OD & * \\
\hline \multirow{5}{*}{ Lutz Golden } & M9 & $71.89^{a}$ & $-12.04^{a b}$ & 38.21 & 45.11 & 106.37ab \\
\hline & M26 & $69.58^{b}$ & $-13.29^{b}$ & 37.49 & 45.01 & $107.99 a$ \\
\hline & MM106 & $72.35^{a}$ & $-11.99^{a}$ & 38.45 & 45.12 & $106.02 b$ \\
\hline & MM111 & $71.14^{a}$ & $-10.81^{a}$ & 37.68 & 44.00 & $105.06 \mathrm{~b}$ \\
\hline & & * & ** & $\mathrm{OD}$ & OD & $* *$ \\
\hline \multirow{5}{*}{ Granny Smith } & M9 & 65.20 & $-15.31^{c}$ & 36.93 & $45.00^{\mathrm{a}}$ & $109.23^{\mathrm{a}}$ \\
\hline & M26 & 66.04 & $-13.25^{a b}$ & 36.75 & $44.11^{\mathrm{a}}$ & $107.26^{\mathrm{b}}$ \\
\hline & MM106 & 64.40 & $-14.69 \mathrm{bc}$ & 35.92 & $44.07^{\mathrm{a}}$ & $110.44^{\mathrm{a}}$ \\
\hline & MM111 & 64.40 & $-12.94^{a}$ & 34.43 & $41.37^{b}$ & $108.41^{\mathrm{a}}$ \\
\hline & & $O D$ & * & $\mathrm{OD}$ & $* *$ & * \\
\hline
\end{tabular}

${ }^{*} p<0.05 ;{ }^{* *} p<0.01 ; O D=$ Önemli değil

Çizelge 6. Denemedeki çeşitlerin fenolojik gözlem tarihleri Table 6. Phacological observation dates of varieties in the trial

\begin{tabular}{|c|c|c|c|c|c|c|}
\hline Çeşit & $\begin{array}{l}\text { Tom. } \\
\text { Kabar. }\end{array}$ & $\begin{array}{l}\text { Tom. } \\
\text { Patla. }\end{array}$ & $\begin{array}{c}\text { İlk Çiçek } \\
(\% 5)\end{array}$ & $\begin{array}{c}\text { Tam çiçek } \\
(\% 70)\end{array}$ & $\begin{array}{l}\text { Çiçek. Sonu } \\
(\% 95)\end{array}$ & $\begin{array}{l}\text { Hasat } \\
\text { Tarihi }\end{array}$ \\
\hline \multirow{2}{*}{\multicolumn{7}{|c|}{ Mondial Gala }} \\
\hline & & & & & & \\
\hline & 25 Mart & 5 Nisan & 21 Nisan & 29 Nisan & 7 Mayıs & 1 Eylül \\
\hline \multirow{2}{*}{\multicolumn{7}{|c|}{ Lutz Golden }} \\
\hline & & & & & & \\
\hline \multirow{2}{*}{\multicolumn{7}{|c|}{ Skyline Supreme }} \\
\hline & & & & & & \\
\hline & 25 Mart & 8 Nisan & 27 Nisan & 30 Nisan & 5 Mayıs & 5 Ekim \\
\hline \multirow{2}{*}{\multicolumn{7}{|c|}{ Granny Smith }} \\
\hline & & & & & & \\
\hline & 25 Mart & 7 Nisan & 25 Nisan & 1 Mayıs & 7 Mayıs & 5 Kasım \\
\hline
\end{tabular}

\section{SONUÇ}

8 yıllık sonuçlara göre, bodur anaçların verim etkinliği yarı bodur anaçlardan daha yüksek olmakla birlikte yarı bodur anaç olan MM106 anacının verim etkinliği yadsınamayacak seviyede yüksektir. Yarı kuvvetli anaç olarak sınıflandırılan MM111 anacı (Barritt, 1992), MM106 anacına göre verimsiz bir anaçtır.
Anaçların meyve kalite kriterlerinden bazılarına etkisi tespit edilmiştir, ancak anaç-çeşit kombinasyonlarının tamamı birlikte değerlendirildiğinde net bir ilişki ortaya konulamamış etkilerin tutarsız olduğu görülmüştür. Eğirdir'de yürütülen bu denemede yer alan çeşitlerin yetiştirilmesinde, herhangi bir ekolojik sorunla karşılaşıımamıştır. 


\section{KAYNAKLAR}

Barritt, B. H., KoNisanhi, B. S. and Dilley, M., 1997. Tree Size, Yield and Biennial Bearing Relationships with 40 Apple Rootstocks and Three Scion Cultivars. Acta Hort. (ISHS) 451:105-112.

Barritt, B., H, Dilley, M. A., and Konishi, A. S., 1994. Influence of Rootstock on 'Delicious' Apple Fruit Shape. Fruit Varieties Journal, 48 (2): 126-130.

Barritt, B. H., Dilley, M. A., and Konishi, B. J., 1992. Apple rootstock performance. Good-Fruit-Grower, 43/11: 6-11.

Barritt, B.H., 1992. Intensive Orchard Management. Good Fruit Grower, Yakima, Washington. p:211.

Burak, M., Büyükyılmaz, M. ve Öz, F., 1994. Yerli ve Yabancı Elma Seçimi III. Bilimsel Araştırma ve İncelemeler. Yayın No:38, Atatürk Bahçe Kültürleri Araştırma Enstitüsü, Yalova

Burak, M., Büyükyılmaz, M. ve Öz, F., 1998. Elma Anaç-Çeşit Adaptasyon Denemesi. Tarımsal Arastırma Özetleri 1996. Tarım ve Köyişleri Bakanlığı, Tarımsal Araştırmalar Genel Müdürlüğü. No: 1, Ankara.

Eren, İ., 2003. Eğirdir Yöresinde Yetiştirilen Bazı Elma Çeşitlerinin Optimum Hasat Zamanları ve Soğuk Depolarda Muhafaza Olanakları Üzerine Araștırmalar. Yüksek Lisans Tezi. T.C. Süleyman Demirel Üniversitesi Fen Bilimleri Enstitüsü (Basılmamış), Isparta.

Ferree, D. C., 1992. Performance of 'Golden Delicious' on Two Rootstocks and Four Dwarfing Interstems Over 10 Years. American Pomological Society Fruit Varieties Journal, Volume 46, Number 2: 93-97.

Fouad, M. M., Khalil, M. A., Mohamed, S. M., Hussein, A. M. and George, A. P., 1995. Effect of rootstock on flowering behaviour, fruit set, yield and fruit characters of Anna apple. In: Fourth International Symposium on Growing Temperate Zone Fruits In The Tropics and Subtropics, 22-26 May 1993, Cairo, Egypt. Acta Horticulturae, No: 409: 251-257.

Granger, R. L., Rousselle, G. L., Meheriuk, M. and Khanizadeh, S., 1992. Performance of 'Cortland' and 'McIntosh' on fourteen rootstocks in Quebec. Fruit-Varieties-Journal, 46: 2: 114-118.

Hampson, R. C. and Kemp, H., 2003. Characteristics of Important Commercial Apple Cultivars (Botany, Production and Uses). In Feree D C \& Warrington I J (Eds.) Apples, CABI Publishing. Cambridge, p: 61-89.

Hussein, I. A. and Slack, D. C., 1994. Fruit Diameter and Daily Fruit Growth Rate of Three Apple Cultivars on Rootstock-Scion Combinations. HortScience, 29: 2: 79-81.

Jackson, J. E., 2003. Biologoy of Horticultural Crops; Biology of Apples and Pears. Cambridge University Press, ISBN O 521 380189, 485 pp.

Janick, J., Cummins, J. N., Brown, S. K. and Hemmat, M., 1996. Apples. In: Janick, J. and Moore, J.N. (eds) Fruit Breeding, Vol.I, Tree and Tropical Fruits. John Wiley \& Sons, New York, pp: $1-77$.
Karaçalı, İ., 2009. Bahçe Ürünleri Muhafazası ve Pazarlanması. E.Ü. Zir. Fak. Yay. No:494. E.Ü. Matbaası. 413 s. Bornova.

Koyuncu, M. A., Eren, İ. ve Özongun, Ş., 2003. M9 ve MM106 Klon Anaçlarının Bazı Elma Çeşitlerinin Meyve Kalitesi Üzerine Etkisi. S. D. Ü. Fen Bilimleri Enstitüsü Dergisi, 7(1), s: 64-69.

Öz, F., Burak, M., Büyükyılmaz, M., Özelkök, S. ve Ergun, M. E., 1993. Elma Sık Dikim Denemesi. Atatürk Bahçe Kültürleri Merkez Araştırma Enstitüsü. Bilimsel Araştırma ve İncelemeler Yayın No:18.Yalova

Özongun, Ş., Dolunay, E. M., Öztürk, G., Karakuş, A. ve Pektaş, M., 2009. Elma Çeşit Adaptasyon Denemesi III (Sonuç Raporu). Tarım ve Köyişleri Bakanlığı, Tarımsal Üretimi Geliştirme Genel Müdürlüğü, Eğirdir Bahçe Kültürleri Araştırma Enstitüsü. Yayın No: 36. Eğirdir, s:1-45

Özongun, Ş., Dolunay, E. M., Öztürk, G., Karakuş, A., Kankaya, A. ve Küden, A., 2004. Elma Adaptasyon Denemesi I (Sonuç Raporu). Tarım ve Köyişleri Bakanlığı, Tarımsal Üretimi Geliştirme Genel Müdürlüğü, Eğirdir Bahçe Kültürleri Araştırma Enstitüsü. Yayın No: 22. Eğirdir, s:1-54.

Pamir, M. ve Öz, M. H., 1997. Bazı Elma Anaç-Çeşit Kombinasyonlarının Erzincan Şartlarına Adaptasyonu Üzerine Araştırmalar. Yumuşak Çekirdekliler Sempozyumu. Atatürk Bahçe Kültürleri Araştırma Enstitüsü. Yalova, 69-75 s.

Parry, M. S. and Baird, N., 1971. Apple Rootstock Annual Report for 1971. East Malling Res.Sta.Maidstone. Kent. UK.35 p.

O'Rourke, D., 2003. World Production, Trade, Consumption and Economic Outlook for Apples. In: D. Ferree ve I. Warrington (eds.). Apples: Botany, Production and Uses. CABI Publishing, UK, p: 15-29.

Özongun, S., Eren, İ. ve Öztürk, G., 2002. Türkiye'de Meyve Fidan Üretimi ve Karşılaşılan Başlıca Sorunlar. Ziraat Mühendisliğ Dergisi, Say1 336. s: 32-34.

Schupp, J. R., 1992. Early Performance of Four Apple Cultivars on Mark and Other Rootstocks in Maine. American Pomologica Society Fruit Varieties Journal, Volume 46, Number 2, p: 67-71.

Tareen, M. J., Tareen, A. Q., Kamal, J. A. and Siddıquin, B. N., 2003. Influence of MM-106 and M-9 Root Stocks on Starking Delicious Apple. Internatıonal Journal of Agriculture \& Biology. ISBN: 1560-8530/2003/05-3, p: 339-340.

Tomala, K., Andziak, J., Jeziorek, K. and Dziuban, R., 2008. Influence of Rootstock on the Quality of 'Jonagold' Apples at Harvest and After Storage. Journal of Fruit and Ornamental Plant Research, Vol. 16, p: 31-38

Tustin, D. S., 1990. The Production and Training of Gala. Compact Fruit Tree: 23 , p: $80-82$.

Way, R. D., Aldwinckle, H. S., Lamb, R. C., Rejman, A., Sansavini, S., Shen, T., Watkins, R., Westwood, M. N. and Yoshida, Y., 1990. Apples (Malus). Acta Horticulturae 290: p:3-62. 